\title{
ANALISIS PENGENDALIAN PERSEDIAAN MENGGUNAKAN PENDEKATAN MUSIC 3D (MULTI UNIT SPARES INVENTORY CONTROL-THREE DIMENSIONAL APPROACH) PADA WAREHOUSE DI PT SEMEN INDONESIA (PERSERO) TBK PABRIK TUBAN
}

\author{
Dian Janari', Manzula Maulida Rahman ${ }^{2}$, Adhe Rizky Anugerah ${ }^{3}$ \\ Jurusan Teknik Industri, Fakultas Teknologi Industri, Universitas Islam Indonesia ${ }^{1,2,3)}$ \\ Jl Kaliurang Km. 14,5 Sleman, Yogyakarta 55584 \\ E-Mail :dian.Janari@uii.ac.id ${ }^{l}$
}

\begin{abstract}
Inventory control is a process that is vital to the company's operations, with the aim to prevent the company from stock-outs and to keep costs as optimally as possible to the activities related to the provision. PT. Semen Indonesia as a national cement company in Indonesia has a problem in controlling inventory, including inventory value that exceeds the target, the value of deadstock which reached $R p .80,000,000$, and the number of items that reached 52,700 items.

MUSIC 3D method is an approach that can overcome the problems of inventory control in PT. Semen Indonesia. This method is a theory to group items based on several aspects. In this study, only three elements in MUSIC 3D are applied, which are ABC analysis (value based), SDE (lead time), and FSN (consumption rate) with the sample as many as 990 types of goods.

The results show that the type of CDN products is goods that dominate in the warehouse of PT. Semen Indonesia, with the following characteristics: C (low price with the high volume of quantity), $D$ (lead time $<6$ months) and $N$ (not used $<1$ year) with the percentage reached $32 \%$ from the total quantity in the warehouse of PT. Semen Indonesia.
\end{abstract}

Keywords : Warehouse, Inventory, Music 3D.

\section{PENDAHULUAN}

PT Semen Indonesia (PERSERO) Tbk merupakan suatu industri manufaktur yang bergerak di bidang penyedia produk semen. Pengendalian persediaan bahan baku dan juga spare part yang mendukung, merupakan proses internal yang cukup vital bagi operasional perusahaan semen karena banyaknya mesin serta target produksi yang mendesak perusahaan untuk menimbun persediaan bahan baku dan spare parts untuk memenuhi permintaan user (Graystone, 1997).

Tujuan dari pentingnya melakukan pengendalian persediaan antara lain mampu menjaga agar perusahaan tidak mengalami kehabisan persediaan yang menyebabkan proses produksi terhenti, selain itu juga menjaga agar penentuan persediaan perusahaan tidak terlalu besar sehingga biaya yang berkaitan dengan persediaan dapat ditekan, dan tujuan lainnya yaitu menjaga agar pembelian bahan baku dapat ditentukan dengan nilai se-optimal mungkin (Assauri, 1998).

Berkaitan dengan pengendalian persediaan PT Semen Indonesia Tbk memiliki masalah mengenai hal ini. Berdasarkan pemaparan dari bagian Seksi Perencanaan Bahan dan Produksi di perusahaan PT Semen Indonesia bahwa target dari nilai inventory hanya 10\% dari total asset perusahaan, dimana asset perusahaan hingga tahun ini mencapai 6 Triliun rupiah, ini berarti target nilai inventory dari perusahaan hanya $\mathrm{Rp}$ 600.000.000,00. Untuk itu, jika ditinjau dari kondisi saat ini, perusahaan telah melebihi target yang seharusnya untuk nilai inventory yaitu sebesar Rp 400.000.000,00. Selain itu, perusahaan juga mengalami kesulitan terhadap banyaknya barang dead stock yang jika dikonversikan menjadi uang mencapai nilai $\mathrm{Rp}$ 80.000.000,00, hal ini juga didukung dengan nilai brick expired yang mencapai Rp 27.000.000,00. Sementara itu, 
jumlah ketersediaan material yang harus dikendalikan juga sangat besar yaitu sebanyak 52.700 item. Dan masalah pengendalian persediaan yang terakhir yaitu berkaitan dengan nilai ITO (Inventory Turn Over) yang tinggi yaitu mencapai 450 hari.

Berdasarkan masalah - masalah diatas, keseluruhan masalah yang timbul di perusahaan PT Semen Indonesia berkaitan dengan manajeman persediaan. Salah satu hal penting yang dapat dijadikan tolak ukur keberhasilan suatu manajemen persediaan adalah proses perencanaan terhadap pengadaan untuk material dan bahan pendukung proses produksi. Begitupun yang terjadi nyatanya di perusahaan PT Semen Indonesia. Permasalahan yang muncul dapat terselesaikan dan terurai dengan melakukan perencanaan terhadap persediaan dengan baik. Namun, yang menjadi tantangan dalam proses perencanaan pengadaan adalah banyaknya jumlah material yang perlu dikendalikan saat ini oleh PT Semen Indonesia. Hal ini menjadikan perusahaan kesulitan dalam menentukan prioritas dan kebijakan terbaik untuk mangendalikannya. Untuk itu, diperlukan suatu metode yang mampu menentukan prioritas serta kebijakan yang dapat melakukan pengendalian persediaan dengan baik sesuai dengan kondisi dari material ataupun bahan pendukung proses produksi.

\section{METODE PENELITIAN}

Dalam menjawab permasalahan mengenai pengendalian persediaandi PT Semen Indonesia PERSERO Tbk akan menggunakan analisis MUSIC 3D, dimana metode ini merupakan kombinasi dari beberapa analisis metode yaitu ABC klasifikasi, SDE klasifikasi, serta FSN klasifikasi.

\subsection{MUSIC 3D Classification}

Dalam Bukunya, (Banerji, 2004) menjelaskan bahwa MUSIC-3D adalah kepanjangan dari Multi Unit Spares Inventory Control - Three Dimensional approach. Teori ini merupakan suatu teori yang dibuat untuk mengelompokkan spare parts ataupun bahan pendukung produksi berdasarkan beberapa aspek yang di butuhkan suatu perusahaan. Terdapat beberapa pendekatan dalam pengelompokan spare parts dan bahan pendukung (Gorana, 2016), antara lain :

Tabel 1. Jenis Klasifikasi Material

\begin{tabular}{|c|c|c|}
\hline No. & Kategori & Kriteria \\
\hline 1. & ABC Analysis & $\begin{array}{c}\text { Nilai } \\
\text { penggunaan } \\
\text { (Quantity* } \\
\text { Harga) }\end{array}$ \\
\hline 2. & $\begin{array}{l}\text { HML (High, } \\
\text { Medium, Low) } \\
\text { Analysis }\end{array}$ & Harga per unit \\
\hline 3. & $\begin{array}{l}\text { VED ( Vital, } \\
\text { Essential, } \\
\text { Desirabel) Analysis }\end{array}$ & $\begin{array}{c}\text { Tingkat } \\
\text { Kekritisan }\end{array}$ \\
\hline 4. & $\begin{array}{l}\text { SDE (Scarce, } \\
\text { Difficullt, Easy) } \\
\text { Analysis }\end{array}$ & $\begin{array}{c}\text { Proses } \\
\text { pengadaan }\end{array}$ \\
\hline 5. & $\begin{array}{l}\text { GOLF (Govt, } \\
\text { Ordinary, Local, } \\
\text { Foreign) Analysis }\end{array}$ & $\begin{array}{c}\text { Teknis } \\
\text { pembayaran } \\
\text { berdasarkan } \\
\text { lokasi supplier }\end{array}$ \\
\hline 6. & $\begin{array}{l}\text { SOS (Seasonal, Off- } \\
\text { Season) Analysis }\end{array}$ & Musiman \\
\hline 7. & $\begin{array}{l}\text { FSN (Fast, Slow, } \\
\text { Non-Moving) } \\
\text { Analysis }\end{array}$ & Laju pakai \\
\hline
\end{tabular}

Berdasarkan beberapa kategori tersebut MUSIC 3D merupakan penggabungan klasifikasi yang menggunakan pendekatan dengan tiga dimensi. Dalam kasus ini dimensi yang digunakan berdasarkan kondisi perusahaan yaitu analisis $\mathrm{ABC}$, analisis FSN, dan juga analisis SDE.

\subsection{ABC Classification}

Klasifikasi ABC merupakan klasifikasi dari suatu kelompok material dalam susunan menurun berdasarkan biaya penggunaan material itu per periode waktu (harga per unit di kalikan volume penggunaan dari material itu selama periode tertentu) (Ginting, 2007). Pada dasarnya terdapat sejumlah faktor yang menentukan kepentingan suatu material, yaitu : 
a. Nilai total uang dari material.

b. Biaya per unit dari material.

c. Kelangkaan atau kesulitan memperoleh material.

d. Ketersediaan sumber daya, tenaga kerja, dan fasilitas yang dibutuhkan untuk membuat material.

e. Panjang variasi waktu tunggu (lead time) dari material, sejak pemesanan material pertama kali hingga kedatangannya.

f. Ruang yang dibutuhkan untuk menyimpan material itu.

g. Resiko penyerobotan atau pencurian material itu.

h. Biaya kehabisan stock atau persediaan (stockout cost) dari material itu.

i. Kepekaan material terhadap perubahan desain.

Klasifikasi ABC mengikuti prinsip 8020, atau hokum Pareto, dimana sekitar $80 \%$ dari nilai total inventori material dipresentasikan (diwakili) oleh 20\% material inventory.

\subsubsection{Penggunaan Klasifikasi $A B C$}

Penggunaan analisis $\mathrm{ABC}$ adalah untuk menetapkan :

a. Frekuensi perhitungan inventori (cycle inventory), di mana material - material kelas A harus di uji lebih sering dalam hal akurasi catatan inventory dibandingkan material - material kelas B dan C.

b. Prioritas rekayasa (engineering), dimana material - material kelas A dan B memberikan petunjuk pada bagian rekayasa dalam peningkatan program reduksi biaya ketika mencari materialmaterial tertentu yang perlu difokuskan.

c. Prioritas pembelian (perolehan), dimana aktivitas pembelian seharusnya difokuskan pada bahan-bahan baku bernilai tinggi (high usage). Fokus pada material-material kelas A untuk pemasokan (sourcing) dan negoisasi.

d. Keamanan : meskipun nilai biaya per unit merupakan indikator yang lebih baik di bandingkan nilai penggunaan (usage value), namun analisis $\mathrm{ABC}$ boleh digunakan sebagai indikator dari material-material mana (A dan B) yang seharusnya aman disimpan dalam ruangan terkunci untuk mencegah kehilangan, kerusakan, atau pencurian.

\subsection{SDE Classification}

SDE klasifikasi merupakan klasifikasi dengan mengelompokkan material berdasarkan nilai lead time suatu material. Terdapat tiga tingkatan dalam SDE analisi. Tingkatan untuk masing - masing kategori adalah sebagai berikut :

Tabel 2. Pembagian Kategori SDE Klasifikasi

\begin{tabular}{ccc}
\hline No. & Kategori & Lead Time \\
\hline 1. & S (Scarce / Langka) & $>6$ bulan atau \\
& & 180 hari \\
2. & $\mathrm{D}$ (Difficult / Sulit) & $\leq 6$ bulan atau \\
& \multicolumn{1}{c}{180 hari } \\
3. & E (Easy/Mudah) & 0 \\
\hline \multicolumn{3}{c}{ (Sumber : Seksi Perencanaan Persediaan Bahan } \\
dan Produksi)
\end{tabular}

\subsection{FSN Classification}

FSN Klasifikasi merupakan klasifikasi dengan mengelompokkan material berdasarkan laju konsumsi suatu material. Terdapat tiga tingkatan dalam FSN analisis. Tingkatan untuk masing - masing kategori adalah sebagai berikut :

Tabel 3. Pembagian Kategori FSN Klasifikasi

\begin{tabular}{|c|c|c|}
\hline No. & Kategori & Keterangan \\
\hline 1. & F (Fast Moving) & $\begin{array}{l}>1 \quad \text { kali } \\
\text { pemakaian dalam } \\
\text { kurun waktu satu } \\
\text { tahun }\end{array}$ \\
\hline 2. & S (Slow Moving) & $\begin{array}{l}=1 \quad \text { kali } \\
\text { pemakaian dalam } \\
\text { kurun waktu satu } \\
\text { tahun }\end{array}$ \\
\hline 3. & $\mathrm{~N}$ (Non-Moving) & $\begin{array}{l}0 \text { atau tidak ada } \\
\text { pemakaian dalam } \\
\text { kurun waktu satu } \\
\text { tahun }\end{array}$ \\
\hline
\end{tabular}

(Sumber : Seksi Persediaan (Inventory) Tuban,2016) 


\section{HASIL PENELITIAN DAN PEMBAHASAN}

Data yang digunakan dalam penelitian ini yaitu sejumlah 990 material. Tidak semua data material yang digunakan dalam penelitian ini, hal ini dikarenakan hanya sejumlah data berikut ini yang lengkap dan telah memenuhi proses pre-processing data. Pengolahan data dilakukan dengan tiga metode klasifikasi utama yaitu meliputi klasifikasi ABC, SED, dan juga FSN. Hasil dari masing - masing metode ini kemudian dijadikan sebagai materi klasifikasi penggabungan untuk metode MUSIC 3D ( Multi Units Spares Inventory Control Using Three Dimensonal Approch ). Berikut adalah hasil dari masing - masing metode klasifikasi :

\subsection{Hasil ABC Classification}

Dalam klasifikasi ABC prinsip yang digunakan adalah prinsip diagram parreto yaitu 80 / 20. Dalam klasifikasi ini data yang dibutuhkan yaitu mengenai data jumlah kuantitas material yang tersedia saat ini (on hand) dengan harga untuk setiap material. Material yang termasuk kedalam kategori A merupakan material yang memiliki nilai / harga yang mempengaruhi nilai inventori paling tinggi namun jumlahnya hanya $20 \%$ dari total material. Sementara, kategori B adalah material yang memiliki nilai harga yang cukup mahal dan jumlahnya $30 \%$ dari total material yang ada dan kategori terakhir adalah kategori $\mathrm{C}$, kategori ini adalah material yang memiliki harga murah dan jumlahnya banyak dengan mewakili 50\% dari total material. Berikut merupakan hasil dari klasifikasi $\mathrm{ABC}$ :

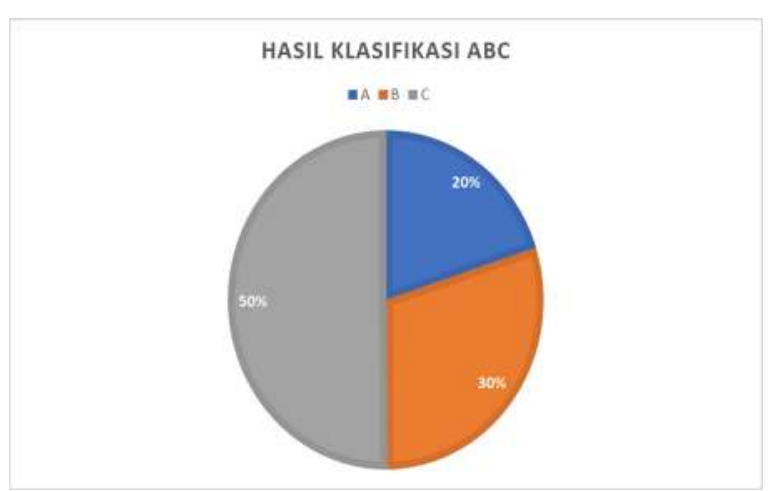

Gambar 1. Hasil ABC Classification.

Berdasarkan hasil klasifikasi yang telah dilakukan, didapatkan bahwa dari total material sejumlah 990 item. 198 item termasuk kedalam kategori A. 296 item termasuk kedalam kategori B. dan 496 item termasuk kedalam kategori $\mathrm{C}$.

\subsection{Hasil FSN Classification}

Klasifikasi FSN merupakan klasifikasi yang didasarkan pada jumlah pemakaian material dalam kurun waktu satu tahun. Berdasarkan Seksi Perencanaan Bahan dan Produksi, material termasuk kedalam kategori F (Fast Moving ) adalah material yang laju pemakaiannya lebih dari satu kali dalam satu tahun. Sementara itu, kategori S (Slow Moving) adalah material yang laju pemakaiannya adalah satu kali dalam satu tahun. Kemudian material yang termasuk pada kategori N (Non Moving) adalah material yang tidak memiliki laju pemakaian sama sekali dalam satu tahun atau laju pemakaiannya sama dengan nol. Berikut merupakan hasil dari FSN Klasifikasi :

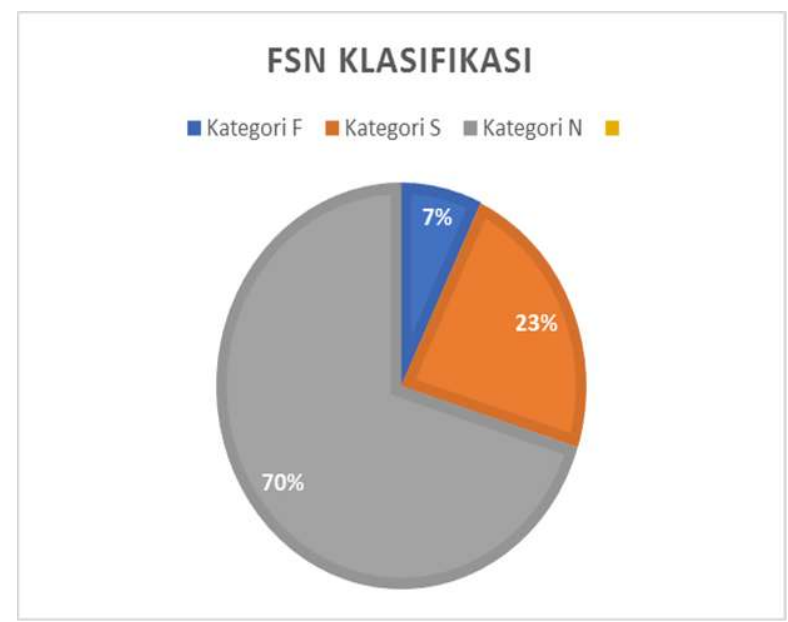

Gambar 2. Hasil FSN Klasifikasi. 
Berdasarkan gambar diatas, dapat diketahui bahwa kategori N (Non Moving) adalah material terbanyak yang terdapat pada perusahaan semen indonesia yaitu sebanyak 694 item material atau $70 \%$ dari total material yang tersedia. Berikutnya, pada kategori S (Slow Moving) terdapat sebanyak 226 item material atau $23 \%$ dari total material yang tersedia. Dan sisanya adalah hanya 70 item yang termasuk kedalam kategori F (Fast Moving) atau 7\% dari total material yang tersedia di warehouse perusahaan.

\subsection{Hasil SDE Classification}

Klasifikasi SDE adalah klasifikasi yang di dasarkan pada nilai lead time untuk masing - masing material. Lead time merupakan waktu yang dibutuhkan untuk satu material produk dari terbitnya PO (Purchase Order) hingga barang tersebut diterima oleh bagian penerimaan (receiving) di warehouse perusahaan. Pembagian masing - masing klasifikai SDE berdasarkan nilai lead time adalah sabagai berikut :

Tabel 4. Pembagian Klasifiksi SDE

\begin{tabular}{|c|c|c|}
\hline No. & Kategori & Lead Time \\
\hline 1. & S (Scarce / Langka) & $\begin{array}{c}>6 \text { bulan atau } \\
180 \text { hari }\end{array}$ \\
\hline 2. & D (Difficult / Sulit) & $\begin{array}{c}\leq 6 \text { bulan atau } \\
180 \text { hari }\end{array}$ \\
\hline 3. & E (Easy / Mudah) & 0 \\
\hline
\end{tabular}

Berdasarkan aturan pembagian kategori seperti pada tabel diatas, berikut merupakan hasil dari klasifikasi SDE untuk material yang terdapat di warehouse semen Indonesia

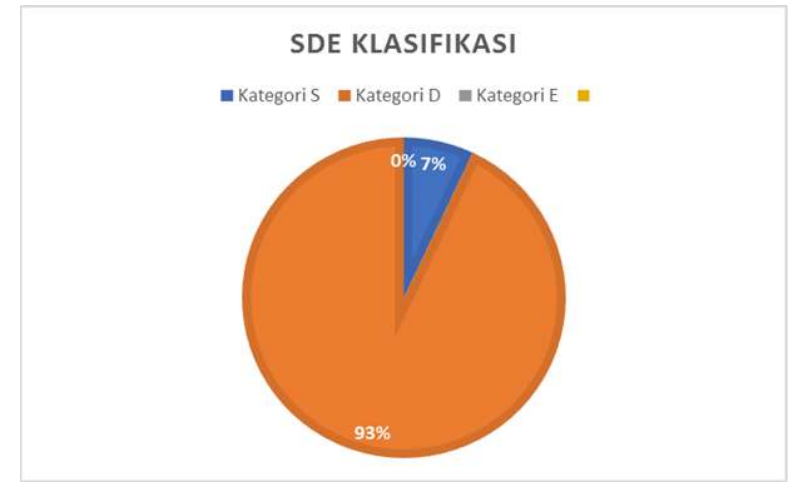

Gambar 3. Hasil SDE Klasifikasi.

Berdasarkan gambar diatas, diketahui bahwa material yang termasuk pada kategori $\mathrm{S}$ atau dapat dikatakan barang tersebut langka adalah sebesar 7\% dari total material atau sejumlah 73 item. Sementara itu, 93\% sisanya termasuk ke dalam kategori D atau sulit untuk terjangkau karena membutuhkan waktu $\leq 6$ bulan. Dan tidak terdapat material yang masuk kedalam kategori E (Easy).

\subsection{Hasil MUSIC 3D Classification}

Klasifikasi MUSIC $3 D$ merupakan klasifikasi yang menggabungkan beberapa dari klasifikasi sebelumnya. Dalam kasus ini, peneliti menggunakan tiga klasifikasi sebelumnya yaitu meliputi klasifikasi $\mathrm{ABC}$, SDE, dan FSN. Berdasarkan ketiga klasifikasi tersebut, metode klasifikasi MUSIC 3D menggabungkannya agar mendapatkan hasil yang spesifik untuk membuat suatu kebijakan pengendalian persediaan nantinya. Berikut merupakan hasil yang didapatkan berdasarkan klasifikasi MUSIC $3 D$ yang dilakukan dimana sumbu x menunjukkan jenis kategori MUSIC $3 D$ dan sumbu y merupakan kuantitas / jumlah dari masing - masing jenis kategori : 


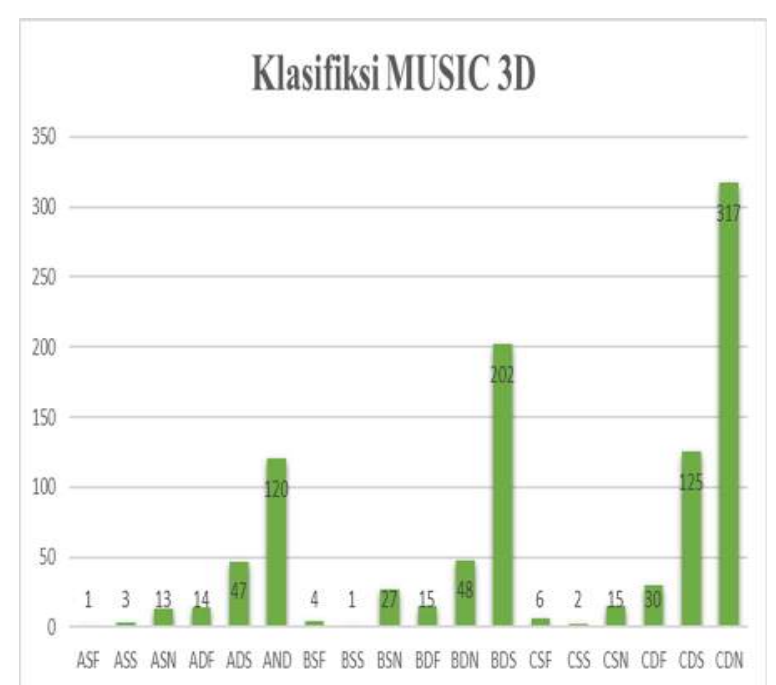

Gambar 4. Hasil Klasifikasi MUSIC 3D.

\subsection{EOQ, ROP, dan SS}

Dalam merespon hasil dari klasifikasi MUSIC 3D, secara metematis solusi pengendaliaan persediaan juga dapat dilakukan yaitu dengan menentukan nilai Economic Order Quantity (EOQ), Safety Stock, dan Reorder Point. Namun, dalam penelitian ini penentuan ketiga hal tersebut hanya di lakukan pada salah satu contoh satu material saja yaitu untuk kategori ASF dengan produk CHEMICAL, RUST TRANSFORMER BARREL CB1405.

a. EOQ (Economic Order Quantity)

EOQ merupakan ukuran pemesanan yang paling ekonomis dan dapat meminimasi biaya - biaya dalam persediaan. Metode ini digunakan untuk menghitung minimasi total biaya persediaan berdasarkan persamaan tingkat titik atau titik equilibrium kurva biaya simpan dan biaya pesan. Berikut merupakan rumus yang digunakan dalam perhitungan EOQ :

$$
\begin{aligned}
& \mathrm{Q}=\sqrt{\frac{2 C_{o} A}{C h}} . \\
& \mathrm{Q}=\sqrt{\frac{2 x 200000 x 2}{20000}} \\
& =6,325=7 \text { unit } \\
& \text { Keterangan : } \\
& \text { Co = Ordering Cost } \text {. } \\
& \mathrm{Ch}=\text { Holding Cost } \text {. } \\
& \mathrm{A}=\text { Permintaan. }
\end{aligned}
$$
$\mathrm{Z}=$ Safety Factor.
$\mathrm{L}=$ Lead Time.
$\mathrm{S}=$ Jumlah Persediaan Sebelum Pesanan Datang.

b. Safety Stock

Safety Stock adalah jumlah cadangan pengaman yang harus ada untuk menjamin kelangsungan proses produksi. Berikut merupakan rumus perhitungan dalam penentuan safety stock:

$$
\begin{aligned}
\mathrm{SS} & =\mathrm{Z} \times \mathrm{S} \times \sqrt{L} \ldots \ldots \ldots \ldots \ldots \\
& =1,65 \times 12 \times 16,911 . \\
& =334.84=335 \text { unit. }
\end{aligned}
$$

c. Reorder Point

Reorder Point adalah metode yang digunakan untuk mengatasi ketidakpastian bahan baku / spare parts dari luar perusahaan untuk mengetahui titik kembali yang paling optimal. Berikut merupakan rumus perhitungan dalam penentuan reorder point :

$$
\begin{aligned}
\mathrm{ROP} & =(\mathrm{D} \times \mathrm{L})+\mathrm{SS} \\
& =(2 \times 286)+335 \\
& =907 \text { unit }
\end{aligned}
$$

Berdasarkan hasil perhitungan secara statistik menggunakan EOQ, SS, ROP untuk salah satu material yang masuk kedalam kategori ASF ternyata hal ini justru akan menambah nilai inventori yang semakin besar, untuk itu dapat dikatakan bahwa solusi ini tidak cocok jika digunakan untuk kategori ASF atau material yang mahal, lead time yang panjang serta laju pemakaiannya fast moving.

\subsection{Pembahasan Hasil MUSIC 3D}

Berikut merupakan analisis kebijakan yang dapat diterapkan dalam perusahaan ditinjau dari kategori yang telah dihasilkan : 
Tabel 5. Hasil Analisis MUSIC 3D

\begin{tabular}{|c|c|c|c|}
\hline No & Gategori & umlah & Analisis Kebijakan Pengendalian Kebijakan \\
\hline 1 & ASF & 1 & $\begin{array}{l}\text { Produk yang termasuk dalam kategori ini produk yang seharusnya } \\
\text { merupakan kontrol ketat utama bagi perusahaan dan } \\
\text { pengawasan dilakukan secara rutin. }\end{array}$ \\
\hline 2 & ASS & 3 & $\begin{array}{l}\text { Produk yang termasuk dalam kategori ini merupakan yang } \\
\text { kontrol perusahaan ketat namun bukan prioritas utama. }\end{array}$ \\
\hline 3 & ASN & 13 & $\begin{array}{l}\text { Untuk produk yang termasuk kategori ini perusahaan perlu } \\
\text { mengeliminasi atau bahkan dalam keadaan low stock. }\end{array}$ \\
\hline 4 & $\mathrm{ADF}$ & 14 & $\begin{array}{l}\text { Produk yang termasuk dalam kategori ini produk yang seharusnya } \\
\text { merupakan kontrol ketat utama bagi perusahaan dan } \\
\text { pengawasan dilakukan secara rutin. }\end{array}$ \\
\hline 5 & ADS & 47 & $\begin{array}{l}\text { Untuk produk yang termasuk kategori ini perusahaan perlu } \\
\text { melakukan kontrol secara berkala tetapi tidak rutin namun } \\
\text { berjangka. }\end{array}$ \\
\hline 6 & $\mathrm{ADN}$ & 120 & $\begin{array}{l}\text { Produk yang termasuk dalam kategori ini merupakan produk yang } \\
\text { kontrol perusahaan lebih longgar dengan dapat mengeliminasi } \\
\text { stock yang ada. }\end{array}$ \\
\hline 7 & BSF & 4 & $\begin{array}{l}\text { Untuk produk yang termasuk kategori ini perusahaan perlu } \\
\text { melakukan kontrol secara berkala tetapi tidak rutin namun } \\
\text { berjangka. }\end{array}$ \\
\hline 8 & BSS & 1 & $\begin{array}{l}\text { Perusahaan hanya perlu melakukan penjadwalan perhitungan } \\
\text { ROP, EOQ dan SS tanpa pengawasan langsung. }\end{array}$ \\
\hline 9 & BSN & 27 & $\begin{array}{l}\text { Perusahaan hanya perlu melakukan pengadaan dalam keadaan low } \\
\text { stock. }\end{array}$ \\
\hline 10 & $\mathrm{BDF}$ & 15 & $\begin{array}{l}\text { Untuk produk yang termasuk kategori ini perusahaan perlu } \\
\text { melakukan kontrol secara berkala tetapi tidak rutin namun } \\
\text { berjangka. }\end{array}$ \\
\hline 11 & BDS & 48 & $\begin{array}{l}\text { Perusahaan hanya perlu melakukan penjadwalan perhitungan } \\
\text { ROP, EOQ dan SS tanpa pengawasan langsung. }\end{array}$ \\
\hline 12 & $\mathrm{BDN}$ & 202 & $\begin{array}{l}\text { Perusahaan hanya perlu melakukan penjadwalan perhitungan } \\
\text { ROP, EOQ dan SS tanpa pengawasan langsung. }\end{array}$ \\
\hline 13 & CSF & 6 & $\begin{array}{l}\text { Produk yang termasuk dalam kategori ini sebaiknya di lakukan } \\
\text { sistem consignment karena resikonya lebih rendah. }\end{array}$ \\
\hline 14 & CSS & 2 & $\begin{array}{l}\text { Produk yang termasuk dalam kategori ini produk yang seharusnya } \\
\text { perusahaan melakukan kelonggaran dalam pengawasan dan } \\
\text { hanya di adakan secara very low stock. }\end{array}$ \\
\hline 15 & CSN & 15 & $\begin{array}{l}\text { Produk yang termasuk dalam kategori ini hanya perlu dibeli saat } \\
\text { kondisi dibutuhkan (JIT) tidak perlu adanya perencanaan } \\
\text { penjadwalan. }\end{array}$ \\
\hline 16 & $\mathrm{CDF}$ & 30 & $\begin{array}{l}\text { Produk yang termasuk dalam kategori ini sebaiknya di lakukan } \\
\text { sistem consignment karena resikonya lebih rendah. }\end{array}$ \\
\hline 17 & CDS & 125 & $\begin{array}{l}\text { Produk yang termasuk dalam kategori ini produk yang seharusnya } \\
\text { perusahaan melakukan kelonggaran dalam pengawasan dan } \\
\text { hanya di adakan secara very low stock. }\end{array}$ \\
\hline 18 & $\mathrm{CDN}$ & 137 & $\begin{array}{l}\text { Produk yang termasuk dalam kategori ini hanya perlu dibeli saat } \\
\text { kondisi dibutuhkan (JIT) tidak perlu adanya perencanaan } \\
\text { penjadwalan. }\end{array}$ \\
\hline
\end{tabular}


Untuk merespon hasil klasifikasi menggunakan MUSIC $3 D$ pengendalian persediaan secara teoritis dapat juga dengan menentukan nilai Economic Order Quantity (EOQ), Safety Stock (SS), dan Reorder Order Point (ROP). Berdasarkan hasil perhitungan di dapatkan bahwa nilai EOQ, SS, ROP untuk material CHEMICAL, RUST TRANSFORMER BARREL CB 1405 secara berturut adalah 7,335 dan 907 unit.

Nilai hasil perhitungan ini dapat di gunakan oleh perusahaan sebagai salah satu pertimbangan dalam proses perencanaan untuk pengadaan produk CHEMICAL, RUST TRANSFORMER BARREL CB1405.

\section{KESIMPULAN}

Berdasarkan hasil yang telah didapatkan, dapat disimpulkan bahwa :

a. Jika dilihat dari hasil ABC klasifikasi diketahui bahwa klasifikasi ini akan memberikan informasi khusus bagaimana besar pengaruh suatu kategori material terhadap besarnya nilai inventori yang akan dipengaruhi. Hasil klasifikasi ini akan memberikan informasi mengenai pengendalian persediaan agar didapatkan nilai inventori yang ideal dan dilihat dari pembuatan kebijakan untuk masing masing kategorinya.

b. Dapat diketahui bahwa hasil dari klasifikasi SDE memberikan informasi yang penting, khususnya untuk bagian pengadaan dan perencanaan di perusahaaan untuk membuat suatu kebijakan dalam penentuan waktu pembelian ataupun penerbitan PO (Purchase Order) pada suatu material kepada pihak vendor dilihat dari hasil kategori yang telah dihasilkan berdasarkan kepada nilai lead time masing - masing kategori.

c. Berdasarkan hasil dari FSN klasifikasi perusahaan mampu mengetahui hasil evaluasi dari material tertentu sesuai dengan laju pemakaian dari suatu material. Selain itu, perusahaan juga dapat mempersiapkan atau melakukan perencanaan ulang terhadap suatu material agar material tersebut tidak masuk dalam kategori dead stock yang akan merugikan perusahaan.

d. Jika dilihat dari hasil klasifikasi secara gabungan dengan klasifikasi MUSIC 3D, perusahaan akan mengetahui tidak hanya dalam satu sisi misalnya hanya dalam sisi harga, melainkan perusahaan dapat membuat suatu kebijakan secara agregat di lihat dari masing - masing kategori yang telah terbentuk. Bentuk dari kebijakan yang dihasilkan dari masing masing kategori berupa kebijakan untuk melakukan pengendalian persediaan di perusahaan semen indonesia Tbk pabrik tuban. Selain itu, dapat juga dilakukan strategi lanjutan dengan menentukan nilai EOQ, SS, dan ROP sesuai dengan kategori yang cocok menggunakan strategi perhitungan secara matematis tersebut.

\section{DAFTAR PUSTAKA}

Assauri, S. Manajeman Produksi dan Operasi.Edisi Revisi. Jakarta: BPFE UI, 1998.

Banerji, P \& Gopalakhrisnan. Maintenance and Spareparts Management . PHI Learning Pvt, 2004.

Ginting, R. Sistem Produksi . Yogyakarta: Graha Ilmu, 2007.

Gorana, S. S \& Dr.Vinjay. Frame Work For Spare Parts Inventory Cost Optmization And Adequacy in Stock Control Management Using Technique of Multi Unit Selective Inventory Control : Perspective to Downstream Plants of Petroleum Industry . International Journal of Science Technology and Management, 145, 2016.

Graystone, J. Surface Coatings International, Part B: Coating Transactions. Chemistry and Materials Science, Vol. 80, No. 11, 516-524, 1997. 